\title{
Evaluation of three cryoprotectants used with bovine milk affected with Mycoplasma bovis in different freezing conditions
}

\author{
Abd Al-Bar Al-Farha ${ }^{1,2^{*}} \mathbb{0}$, Manouchehr Khazandi ${ }^{1,3}$, Farhid Hemmatzadeh ${ }^{1,3}$, Razi Jozani ${ }^{5}$, Rick Tearle ${ }^{1,4}$, \\ Andrew Hoare ${ }^{6}$ and Kiro Petrovski ${ }^{1,3,4}$
}

\begin{abstract}
Objectives: Currently, there is no consensus protocols regarding the combination of glycerol (GLY), gelatin or foetal bovine serum (FBS) with dimethyl sulphoxide (DMSO) as cryoprotectants for Mycoplasma bovis in bovine milk samples. This study aimed to compare different cryopreservation compounds and storage temperatures for M. bovis.

Results: There were significant differences in the survival of $M$. bovis on different media. Differences were also observed between different storage conditions. All additives improved the survival of $M$. bovis in comparison to control (CON). The combination of GLY and DMSO was shown to be significantly different to CON with 57.1\% (95\% $\mathrm{Cl}=21.43-133.34)$ and $19.1 \%(95 \% \mathrm{Cl}=11.73-60.27)$, respectively at week 16 , and its use should be encouraged as a cryoprotectant for M. bovis at -20 and $-80^{\circ} \mathrm{C}$. GEL/DMSO showed the highest survival rate for M. bovis with $57.14 \%(95 \% \mathrm{Cl}=21.43-133.34)$ at $4{ }^{\circ} \mathrm{C}$ in comparison with CON $14.29 \%(95 \% \mathrm{Cl}=9.60-50.39)$. FBS/DMSO showed the highest survival rate for the short-term preservation similarly to other additives. The evaluated cryopreservative compounds would improve survivability of $M$. bovis in milk for both transport and long-term storage. Hence, it is recommended to use the mentioned methods for routine transportation or storage purposes for suspicious M. bovis milk samples.
\end{abstract}

Keywords: Mycoplasma bovis, Mastitis, Cryopreservation, Glycerol, DMSO, Gelatin

\section{Introduction}

Mycoplasma bovis mastitis is increasingly generating considerable interest in the bovine dairy industry. The current method for isolation of mycoplasmas is using specific mycoplasma culture media. For this purpose, milk samples are sent as frozen or fresh to diagnostic laboratories. An important factor for successful bacterial isolation is to keep Mycoplasma organisms viable for growth. Consequently, appropriate sample handling and storage is the main key for diagnosis or research purposes. Due to the lack of cell wall, viability of $M$. bovis under freeze-thaw conditions is a significant challenge in short and long-term preservation. Previous studies

\footnotetext{
*Correspondence: abdal-barahmednoori.al-farha@adelaide.edu.au ${ }^{1}$ School of Animal and Veterinary Sciences, The University of Adelaide, Roseworthy, Adelaide, SA 5371, Australia

Full list of author information is available at the end of the article
}

have focused on different animal sources of mycoplasmas rather than bovine milk $[1,2]$. For bovine milk, standard protocols for prolonged storage of non-Mycoplasma mastitis pathogens have been proposed [3-5]. However, these protocols are not applicable to $M$. bovis due to the structural variation between these bacteria and conventional mastitis pathogens. Furthermore, farmers commonly freeze collected milk samples for submission to the diagnostic labs as part of their mastitis management program or if mastitis is a perceived problem on their farm (e.g. increase in incidence of mastitis or treatment failure). Preserving the collected milk is the most important step for bacterial isolation/detection in both bacteriological and molecular methods. A cornerstone for prospective microbiological studies is successful culture of Mycoplasma. For routine culture of Mycoplasma mastitis, the use of fresh milk samples has 
been recommended [6]. However, preserved milk samples should be considered. Thus, appropriate storage conditions are required to obtain maximal survival of $M$. bovis. A dearth of knowledge regarding appropriate storage of milk samples, both for farmers and researchers, is evident. This study evaluated survival of $M$. bovis in bovine milk following various storage times under three different temperature storage conditions $(4,-20$ and $\left.-80^{\circ} \mathrm{C}\right)$ using milk only as a control $(\mathrm{CON})$ or three different storage media [milk supplemented with dimethyl sulphoxide (DMSO) and foetal bovine serum (FBS), gelatin (GEL) or glycerol (GLY)].

\section{Main text \\ Methods \\ Milk samples}

As part of a previous study, milk samples were collected aseptically from 288 cows at individual cow-level from a single commercial dairy farm near Mount Gambier in South Australia [7]. All samples were subjected to cryopreservation, culture and PCR. In this study, twenty-one positive samples for M. bovis were selected based on positive culture and PCR results.

\section{Bovis culture}

Milk samples were subjected to Mycoplasma culture using Mycoplasma selective media (Oxoid, Sydney, Australia) according to the manufacturer's instructions. Mycoplasma colonies were counted using a stereomicroscope at $10 \times$ magnification after 7-14 days. Cultures were considered positive when a minimum of one $M$. bovis colony was recorded [8]. At the moment of counting the person who carried out the procedure was not aware of the group allocation. The initial concentration of the organisms in each milk sample was calculated at week 0 for all samples.

\section{Identification of $M$. bovis by $P C R$}

DNA was extracted directly from milk using QIAmp DNA extraction kit (Qiagen, Germany) according to the manufacturer's instructions. Specific 16S rRNA primers designed for M. bovis (442 bp), composed of MbovF: $5^{\prime}$-CCAGCTCACCCTTATACATGAGCGC-3' and Mbov-R: 5'-TGACTCACCAATTAGACCGACTATTTC ACC-3'. Amplifications were carried out in $25 \mu \mathrm{L}$ containing $0.25 \mu \mathrm{L}$ Taq DNA polymerase, $5 \mu \mathrm{L}$ of $5 \times$ reaction buffer (Bioline, UK), $1 \mu \mathrm{L}(0.5 \mu \mathrm{M})$ of each forward and reverse primers, $1 \mu \mathrm{L}$ (approximately $20 \mathrm{ng}$ ) of template, and $16.75 \mu \mathrm{L}$ of DEPC-treated water. Amplifications were performed for 35 PCR cycles conditions using $\mathrm{T}_{100}{ }^{\mathrm{TM}}$ Thermal Cycler (Biorad thermocycler, Australia), and consisted of pre-heating activation for $5 \mathrm{~min}$ at $95^{\circ} \mathrm{C}$, denaturation at $95{ }^{\circ} \mathrm{C}$ for $30 \mathrm{~s}$, annealing at $60{ }^{\circ} \mathrm{C}$ and primer extension at $72{ }^{\circ} \mathrm{C}$ for $45 \mathrm{~s}$. The final extension step was performed at $72{ }^{\circ} \mathrm{C}$ for $10 \mathrm{~min}$. The PCR products were analysed by $1.5 \%$ agarose gel electrophoresis and visualised by staining with Gel Red.

\section{Evaluating storage-recovery of $M$. bovis}

The following storage media were selected for this study: (a) milk supplemented with $40 \%$ FBS and 10\% DMSO (treatment group FBS), (b) milk supplemented with $40 \%$ GEL (conc. $150 \mathrm{~g} / \mathrm{L}$ ) and 10\% DMSO (treatment group GEL), (c) milk supplemented with 40\% GLY and 10\% DMSO (treatment group GLY), and (d) milk alone (treatment group CON). For each preparation, $8 \mathrm{~mL}$ of each $M$. bovis positive milk sample were added into $8 \mathrm{~mL}$ of each storage medium, and CON. Each of the diluted samples was aliquoted into 15 Eppendorf tubes $(1 \mathrm{~mL}$ each) at the same day of collection. For each storage medium, five tubes of aliquots was stored at $4,-20$ or $-80{ }^{\circ} \mathrm{C}$. There were therefore 21 samples $\times 4$ storage media $\times 3$ storage conditions $\times 5$ time points, totalling 1260 combinations. At each particular time point, one aliquot from each storage media was thawed and cultured onto $\mathrm{Myco}$ plasma selective media as described above.

\section{Statistical analysis}

The data were binomially distributed $(0=$ no recovery; $1=$ recovery). Hence, a generalised linear model using $(R$ version 3.1.1, R Development Core Team, New Zealand) package was run for the dataset. The predicted survival was estimated accounting for the fixed effect of storage media (FBS, GEL, GLY, or CON), time (weeks), storage condition $\left(4,-20\right.$ or $\left.-80^{\circ} \mathrm{C}\right)$, and their three-way interaction. Means of survival as rate, $95 \%$ confidence intervals, and differences between means were obtained, and are used in the comparison between storage media, time and storage conditions. Survival analysis per treatment group was also carried out and results are presented as figures.

Analysis of variance (ANOVA) using MIXED of the SAS of the number of colony-forming units (CFUs) per plate at each time point was estimated accounting for the fixed effect of storage media (FBS, GEL, GLY, or CON), time (weeks), storage condition $\left(4,-20\right.$ or $\left.-80^{\circ} \mathrm{C}\right)$, and their three-way interaction. Means of CFU, standard errors and were obtained, and are used in the comparison between storage media, time and storage conditions.

\section{Results}

The viability of $M$. bovis for the 21 milk samples after storage at different temperature conditions and milk alone or in combination with three different cryoprotectants (treatment groups FBS, GEL, GLY or CON) are shown in Fig. 1. A significant differences in survival 

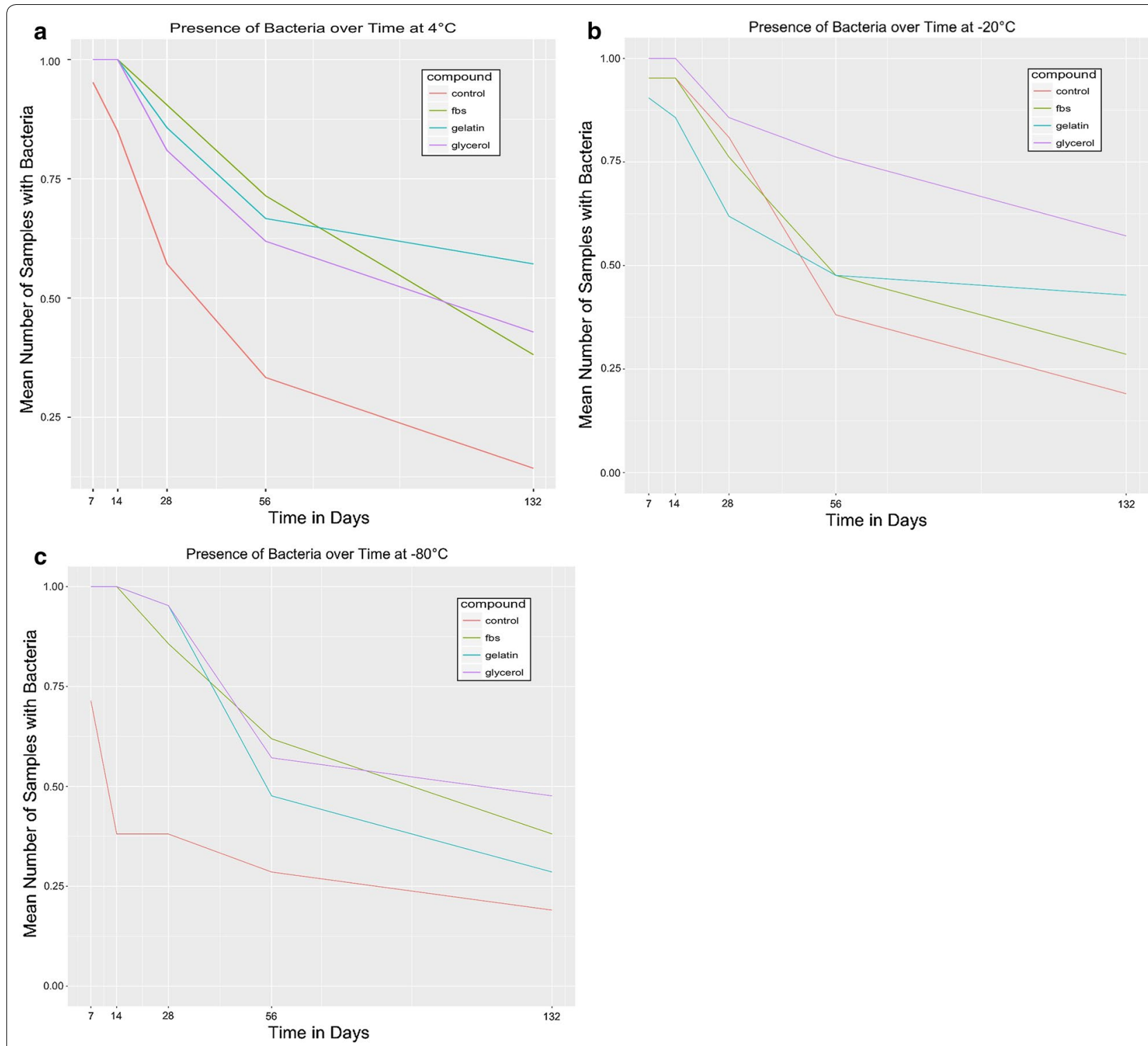

Fig. 1 Viability percentage of Mycoplasma bovis after storage at domestic fridge $4{ }^{\circ} \mathrm{C}(\mathbf{a})$, domestic freezer $-20^{\circ} \mathrm{C}(\mathbf{b})$, or laboratory freezer $-80^{\circ} \mathrm{C}$ (c) assessed in milk or milk supplemented with Foetal Bovine Serum (40\% v-v) + Dimethyl Sulphoxide (10\% v-v), Gelatin (40\% v-v)+DMSO (10\% v-v) or Glycerol $(40 \%$ v-v) + DMSO (10\% v-v)

rate of $M$. bovis were detected between different cryoprotectants and temperature conditions. In general, all additives improved the survival rate of $M$. bovis in comparison with $\mathrm{CON}$. The highest survival rate for $M$. bovis isolates was observed at $-80{ }^{\circ} \mathrm{C}$ followed by -20 and $4{ }^{\circ} \mathrm{C}$. For the long term preservation, GLY was the most effective cryoprotectant; at -20 and $-80{ }^{\circ} \mathrm{C}$ the survival rate was $57.1 \%(95 \% \mathrm{CI}=21.43-133.34)$ and $47.6 \%$ (95\% CI $=20-116.04)$, respectively, in comparison with $\mathrm{CON} 19.1 \%$ (95\% $\mathrm{CI}=11.73-60.27)$ in week 16. GEL showed highest $M$. bovis survival rate at $4{ }^{\circ} \mathrm{C}$ with $57.1 \%$ (95\% CI $\left.=21.4-133.34\right)$ in comparison with CON $14.3 \%(95 \% \mathrm{CI}=9.6-50.39)$ in week 16 . FBS showed the highest survival rate for the short-term preservation, similarly to other additives. However, contrary to survivability rates, no significant differences were observed in the CFUs among the survived isolates Table 1. Agarose gel electrophoresis for specific $M$. bovis PCR of all 21 samples tested revealed amplicon size of $442 \mathrm{bp}$. 


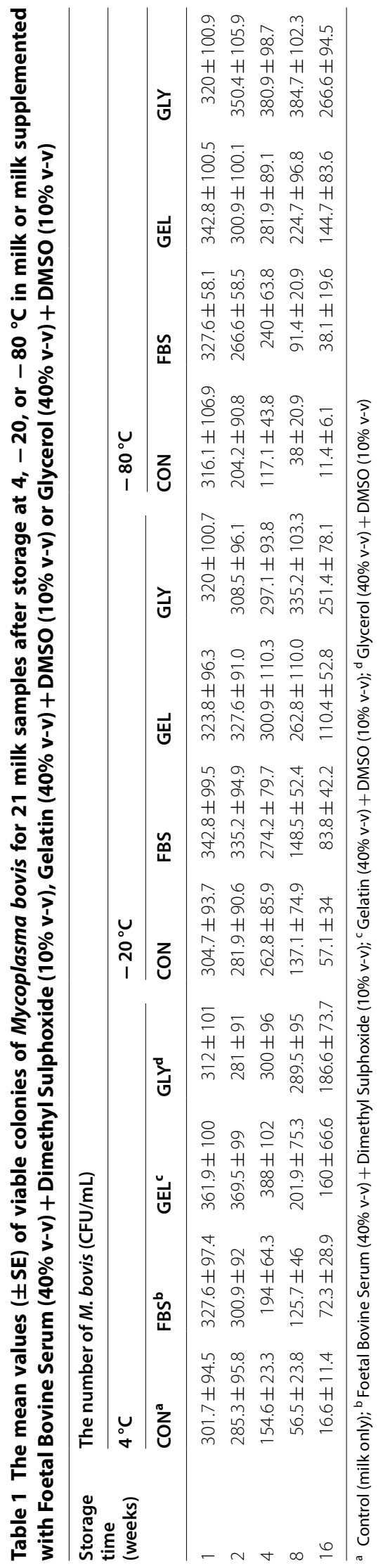




\section{Discussion}

The effect of M. bovis viability under freeze-thaw conditions is a significant challenge in preservation of these bacteria. Lacking of peptidoglycan cell wall in mycoplasmas makes them sensitive to formation of ice crystal during freezing/thawing processes. Sensitivity of Mycoplasma spp. to freezing injuries due to phospholipid membrane lipids leakage has been reported in previous studies [9]. M. bovis is a fastidious pathogen, and its survival during storage is often affected by both bacterial overgrowth and $\mathrm{pH}$ alteration of milk [10]. Intracellular and extracellular ice crystallisation play an important role in cell damage during freezing processes $[9,11]$. Our results indicated maximal survival rate of isolates after short- and long-term storage in the treatment group GLY. We hypothesise that optimum survival in freezing conditions containing DMSO was a result of prevention of formation of intracellular ice crystals [12]. GLY has a similar role in cryopreservation that likely results from binding the hydrogen-hydrogen bonds of water intracellularly [13]. The bacteriostatic activity of GLY contributes to inhibition of other bacterial growth leading to improved survival of Mycoplasma [14]. The effect of DMSO and GLY as cryoprotectants for various kinds of microorganisms has been previously reported [15]. A lower survival was detected when a combination of FBS and DMSO were used. FBS has been used as a preservation for many types of cells either alone or in combination with DMSO. It is hypothesised that FBS protects cells from osmotic shock, in addition to the neutralising activity against toxic materials released from the damaged cell during the freezing process [15-17]. GEL has been previously used as a preservative for various bacterial species [18], and can act as coating factor to cells similar to GLY. Together, these findings demonstrate that the combination of DMSO + GLY significantly preserves the viability of $M$. bovis under different storage conditions. Our results indicated the legitimacy of using a combination of GEL + DMSO solution as well as FBS + DMSO as additives to milk samples stored at different temperatures.

In conclusion, this study revealed that milk samples supplemented with DMSO and GEL or GLY improved the survival of $M$. bovis associated with mastitis. Our cryoprotectants need to be studied for conventional mastitis pathogens. If the results are similar, addition of preservation additives used in this study can be recommended as a routine procedure for transforming or storing milk samples for different purpose processing.

\section{Limitations}

Although there was a dramatic decrease in CFU over the period of preservation points, no significant differences were found. This may be a true effect but may also be due to small sample size. Samples used in this study were not randomly selected. They were selected by chance from the original pool of samples. Hence, one may suspect that the results may not be applicable to the external population. However, in this study each sample had similar chance of being selected for the study, as cows were sampled in non-particular order, and selection of milk samples was in non-particular order as well.

\section{Abbreviations \\ CON: control; GLY: glycerol; GEL: gelatin; FBS: foetal bovine serum; DMSO: dimethyl sulphoxide; CFU: colony forming unit.}

\section{Authors' contributions}

$\mathrm{AA}, \mathrm{MK}$, FH and KP participated in the study design and sample processing. $\mathrm{AA}, \mathrm{FH}$ and $\mathrm{RJ}$ contributed to the bacterial culture and molecular detection. $\mathrm{AA}, \mathrm{AH}, \mathrm{MK}$, and KP contributed to samples collection. KP and RT carried out the statistical analysis. All authors were involved in drafting the manuscript. All authors read and approved the final manuscript.

\section{Author details}

${ }^{1}$ School of Animal and Veterinary Sciences, The University of Adelaide, Roseworthy, Adelaide, SA 5371, Australia. ${ }^{2}$ Mosul Technical Institute, Northern Technical University, Technical Foundation, Mosul, Iraq. ${ }^{3}$ Australian Centre for Antimicrobial Resistance Ecology, The University of Adelaide, Roseworthy, Adelaide, SA 5000, Australia. ${ }^{4}$ Davies Centre, School of Animal and Veterinary Sciences, The University of Adelaide, Roseworthy, Adelaide, SA 5371, Australia. ${ }^{5}$ Department of Veterinary Clinical Sciences, University of Tabriz, Tabriz, Iran.

${ }^{6}$ South East Vets, Mt Gambier, SA 5290, Australia.

\section{Acknowledgements}

We would like to thank the farmer and farm staff for their cooperation and interest in the study.

\section{Competing interests}

The authors declare that they have no competing interests.

\section{Availability of data and materials}

The datasets generated during and/or analysed during the current study are available from the corresponding author on reasonable request.

\section{Consent to publish}

Not applicable.

\section{Ethics approval and consent to participate}

Not applicable. Samples were collected by field veterinary support as a part of the mastitis investigation as per farmer request and no Animal Ethics application was required (Australian code for the care and use of animals for scientific purposes, 8th edition, 2013).

\section{Funding}

The first author was partially funded by The Higher Committee for Education Development in Iraq in form of a scholarship. All field and laboratory procedures were financially supported by the University of Adelaide.

\section{Publisher's Note}

Springer Nature remains neutral with regard to jurisdictional claims in published maps and institutional affiliations. 
Received: 26 January 2018 Accepted: 24 March 2018

Published online: 02 April 2018

\section{References}

1. Addey JP, Taylor-Robinson D, Dimic M. Viability of mycoplasmas after storage in frozen or lyophilised states. J Med Microbiol. 1970;3(1):137-45.

2. Christensen NH, Yavari CA, McBain AJ, Bradbury JM. Investigations into the survival of Mycoplasma gallisepticum, Mycoplasma synoviae and Mycoplasma iowae on materials found in the poultry house environment. Avian Pathol. 1994;23(1):127-43.

3. Petzer I-M, Karzis J, Van der Schans TJ, Watermeyer JC, Mitchell-Innes $\mathrm{N}$, Eloff S, Fosgate GT. Comparing effects of freezing at $-196^{\circ} \mathrm{C}$ and $-20^{\circ} \mathrm{C}$ on the viability of mastitis pathogens. Onderstepoort J Vet Res. 2012;79(1):01-6.

4. Villanueva M, Tyler J, Thurmond M. Recovery of Streptococcus agalactiae and Staphylococcus aureus from fresh and frozen bovine milk. J Am Vet Med Assoc. 1991;198(8):1398-400

5. Schukken Y, Smit J, Grommers F, Vandegeer D, Brand A. Effect of freezing on bacteriologic culturing of mastitis milk samples. J Dairy Sci. 1989;72(7):1900-6.

6. Biddle MK, Fox LK, Hancock DD, Gaskins CT, Evans MA. Effects of storage time and thawing methods on the recovery of Mycoplasma species in milk samples from cows with intramammary infections. J Dairy Sci. 2004:87(4):933-6.

7. Al-Farha AA-B, Hemmatzadeh F, Khazandi M, Hoare A, Petrovski K. Evaluation of effects of Mycoplasma mastitis on milk composition in dairy cattle from South Australia. BMC Vet Res. 2017;13(1):351.

8. Markey B, Leonard F, Archambault M, Cullinane A, Maguire D. Clinical veterinary microbiology. Amsterdam: Elsevier Health Sciences; 2013.
9. Raccach M, Rottem S, Razin S. Survival of frozen mycoplasmas. Appl Microbiol. 1975;30(2):167-71.

10. Boonyayatra S, Fox LK, Besser TE, Sawant A, Gay JM. Effects of storage methods on the recovery of Mycoplasma species from milk samples. Vet Microbiol. 2010;144(1-2):210-3.

11. Mazur P. Physical and chemical basis of injury in single-celled microorganisms subjected to freezing and thawing. In: Meryman HT, editor. Cryobiology. Sapporo: Academic Press; 1966. P. 213-5.

12. Pegg DE. Principles of cryopreservation. In: Day JG, Stacey GN, editors. Cryopreservation and freeze-drying protocols. Berlin: Springer; 2007. p. 39-57.

13. Best B. Cryoprotectant toxicity: facts, issues, and questions. Rejuvenation Res. 2015;18(5):422-36.

14. Roger V, Fonty G, Andre C, Gouet P. Effects of glycerol on the growth, adhesion, and cellulolytic activity of rumen cellulolytic bacteria and anaerobic fungi. Curr Microbiol. 1992;25(4):197-201.

15. Hubalek Z. Protectants used in the cryopreservation of microorganisms Cryobiology. 2003;46(3):205-29.

16. Castro SV, de Carvalho AA, da Silva CMG, Faustino LR, Campello CC, Lucci CM, Báo SN, de Figueiredo JR, Rodrigues APR. Freezing solution containing dimethylsulfoxide and fetal calf serum maintains survival and ultrastructure of goat preantral follicles after cryopreservation and in vitro culture of ovarian tissue. Cell Tissue Res. 2011;346(2):283-92.

17. Mitchell A, Rivas KA, Smith R III, Watts AE. Cryopreservation of equine mesenchymal stem cells in 95\% autologous serum and 5\% DMSO does not alter post-thaw growth or morphology in vitro compared to fetal bovine serum or allogeneic serum at 20 or $95 \%$ and DMSO at 10 or $5 \%$. Stem Cell Res Ther. 2015;6(1):1-12.

18. Obara Y, Yamai S, Nikkawa T, Shimoda Y, Miyamoto Y. Preservation and transportation of bacteria by a simple gelatin disk method. J Clin Microbiol. 1981;14(1):61-6. 